\title{
Aligned silk-based 3-D architectures for contact guidance in tissue engineering
}

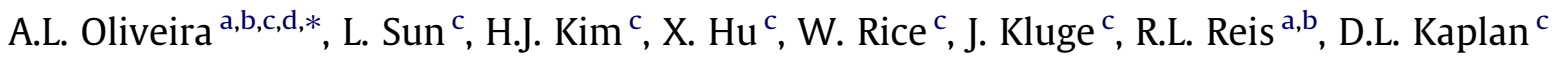 \\ a 3B's Research Group - Biomaterials, Biodegradables and Biomimetics, University of Minho, Headquarters of the European Institute of Excellence on Tissue \\ Engineering and Regenerative Medicine, AvePark, 4806-909 Taipas, Guimarães, Portugal \\ b ICVS/3B's - PT Government Associate Laboratory, Braga/Guimarães, Portugal \\ ${ }^{\mathrm{c}}$ Department of Biomedical Engineering, Tufts University, Medford, MA 02155, USA \\ ${ }^{\mathrm{d}}$ Department of Health Sciences, Portuguese Catholic University, Viseu, Portugal
}

\section{A R T I C L E I N F O}

\section{Article history:}

Received 15 July 2011

Received in revised form 24 October 2011

Accepted 9 December 2011

Available online 16 December 2011

\section{Keywords:}

Silk scaffold

Freeze-drying

Tissue engineering

Lamellar morphology cell alignment

\begin{abstract}
A B S T R A C T
An important challenge in the biomaterials field is to mimic the structure of functional tissues via cell and extracellular matrix (ECM) alignment and anisotropy. Toward this goal, silk-based scaffolds resembling bone lamellar structure were developed using a freeze-drying technique. The structure could be controlled directly by solute concentration and freezing parameters, resulting in lamellar scaffolds with regular morphology. Different post-treatments, such as methanol, water annealing and steam sterilization, were investigated to induce water stability. The resulting structures exhibited significant differences in terms of morphological integrity, structure and mechanical properties. The lamellar thicknesses were $\sim 2.6 \mu \mathrm{m}$ for the methanol-treated scaffolds and $\sim 5.8 \mu \mathrm{m}$ for water-annealed. These values are in the range of those reported for human lamellar bone. Human bone marrow-derived mesenchymal stem cells (hMSC) were seeded on these silk fibroin lamellar scaffolds and grown under osteogenic conditions to assess the effect of the microstructure on cell behavior. Collagen in the newly deposited ECM was found aligned along the lamellar architectures. In the case of methanol-treated lamellar structures, the hMSC were able to migrate into the interior of the scaffolds, producing a multilamellar hybrid construct. The present morphology constitutes a useful pattern onto which hMSC cells attach and proliferate for guided formation of a highly oriented extracellular matrix.
\end{abstract}

(ㄷ) 2011 Acta Materialia Inc. Published by Elsevier Ltd. All rights reserved.

\section{Introduction}

The potential of silk as a biomaterial has been widely recognized, owing to its processing versatility, impressive mechanical performance, biocompatibility, oxygen and water vapor permeability and tailorable degradability [1-3]. Silk fibroin (SF) is a structural protein which can be extracted from larvae cocoons of the species Bombyx mori. In the process of preparing new SF-based biomaterials, microstructure, porosity and surface chemistry are important features that modulate cell behavior, migration and proliferation towards the desired engineered tissue [4]. Based on this knowledge, SF has been generated in a wide variety of morphologies for engineering different tissues in terms of structure and function [5-13].

Most functional tissues, such as musculoskeletal, tendon and ligament, cardiac, nervous and vascular, present significant cell alignment and anisotropic morphologies. To mimic such intricate

\footnotetext{
* Corresponding author at: 3B's Research Group - Biomaterials, Biodegradables and Biomimetics, University of Minho, Headquarters of the European Institute of Excellence on Tissue Engineering and Regenerative Medicine, AvePark, 4806-909 Taipas, Guimarães, Portugal. Tel.: +351 253 510908; fax: +351 253510909.

E-mail addresses: analeite@dep.uminho.pt (A.L. Oliveira), david.Kaplan@tufts. edu (D.L. Kaplan).
}

structures and develop materials with properties/directioncontrolled functions constitutes an important challenge and has attracted considerable interest in recent years. A significant amount of research has been directed towards controlling the spatial organization of cells in well-defined microarchitectures [14-18]. Several techniques have been described to control two-dimensional cellular alignment $[15,17,19]$. However, cellular organization within three-dimensional (3-D) architectures remains challenging. Considerable progress has been achieved using strategies of mechanical [20,21], electrical [22] or magnetic [23] stimulation. Still, there is a need for simple 3-D systems for investigating cell alignment and guidance cues for various cell types without mechanical force or other external stimulation, for a wide range of applications, from tissue engineering to the control of cellular behaviors such as differentiation and function.

The freeze-drying process has been widely exploited for producing viable porous architectures for tissue engineering, mostly in the case of polymer-based systems [24-29]. This technique does not require additional chemicals, relying instead on the water already present in solution/hydrogel to form ice crystals, which can be sublimated from the polymer, creating a particular microarchitecture. The direction of growth and size of the ice crystals are a function of the temperature gradient and concentration of 
the solution. By adjusting these parameters, it is possible control the porosity and pore architecture [24,26,30-32].

In the present work, new SF 3-D architectures with lamellar structures were successfully developed using a freeze-drying technique. The aim was to achieve a high degree of control over the lamellar morphology by varying silk solution concentration and freezing parameters. In order to induce stability of the scaffold morphology, different post-treatments were studied, including methanol, water annealing and steam sterilization (autoclave). Human bone marrow-derived mesenchymal stem cells (hMSC) grown under osteogenic conditions were the selected cell population to investigate the suitability of the lamellar scaffolds produced for generating highly aligned 3-D cell structures. Highly aligned structures such as these can be found in the lamellar bone and also in the intervertebral disk (annulus fibrosus) [33]. To mimic such intricate systems is challenging, and there are only a few examples of lamellar-like structures in the literature $[28,30,34]$. The freeze-drying methodology presented here generates highly reproducible SF lamellar structures with controlled spatial arrangement which is adequate for highly aligned 3-D cell structures. The systems can find use in tissue engineering applications and constitute interesting substrates as models for investigating cell interaction and function in such highly oriented and confined spatial arrangements.

\section{Materials and methods}

\subsection{Preparation of lamellar scaffolds}

Silk solution was prepared using B. mori silkworm cocoons supplied by Tajima Shoji Co (Yokohama, Japan) according to protocols described in previous studies [35,36]. Briefly, cocoons of B. mori were boiled for $20 \mathrm{~min}$ in an aqueous solution of $0.02 \mathrm{M}$ sodium carbonate, and then rinsed thoroughly with pure water. After drying, the extracted SF was dissolved in a ternary solvent, $\mathrm{CaCl}_{2}-$ ethanol-water $(1: 2: 8)$, at $60^{\circ} \mathrm{C}$ for $3 \mathrm{~h}$, yielding a $20 \%(\mathrm{w} / \mathrm{v})$ solution. This solution was dialyzed against distilled water using Slide-a-Lyzer dialysis cassettes (MWCO 3500, Pierce) for 3 days to remove the salt. The final concentration of SF aqueous solution was $\sim 8 \%(\mathrm{w} / \mathrm{v})$. This concentration was determined by weighing the residual solid of a known volume of solution after drying. The solution was then diluted to obtain the following concentrations: 6,4 and $2 \%(\mathrm{w} / \mathrm{v})$. The different samples were cast into silicone molds, frozen at $-80^{\circ} \mathrm{C}$ overnight and freeze-dried (Telstar, Spain) for 2 days. Some of the samples were frozen at $-5^{\circ} \mathrm{C}$ for $4 \mathrm{~h}$ prior to the described freeze-drying process. Samples with diameter $7 \mathrm{~mm}$ and height $4 \mathrm{~mm}$ were produced. In order to induce water-stability to the SF scaffolds, different procedures were used: (i) treatment with a methanol solution (90\%) for $3 \mathrm{~h}$; (ii) water annealing [37] (briefly, the films were kept in a water-filled vacuumed desiccator at $<10^{-3} \mathrm{mmHg}$ for $\sim 24 \mathrm{~h}$ ); and (iii) steam sterilization $\left(120^{\circ} \mathrm{C}\right.$, $15 \mathrm{psi}$, for $20 \mathrm{~min}$; total cycle time, $1 \mathrm{~h}$ ). A scheme of the procedure is presented in Fig. 1.

\subsection{Scanning electron microscopy}

The cross sections of the lamellar scaffolds produced prior to and after the different treatments were examined by scanning electron microscopy (SEM). The samples were sputter coated with gold and examined with a LEO Gemini 982 Field Emission Gun SEM (Oberkochen, Germany).

\subsection{Confocal and multiphoton microscopy}

The different scaffolds were observed by confocal and multiphoton microscopy. A confocal microscope (Bio-Rad MRC 1024, Hercu- les, CA) with Lasersharp 2000 software (excitation/emission 495/ $515 \mathrm{~nm}$ ) was used for imaging. The region of interest was selected from $z$-plane images to include either the surface or the internal pores, beginning with a bottom section at least $1 \mathrm{~mm}$ above the surface of the scaffolds. Depth projection micrographs were obtained from 20 horizontal sections imaged at a depth distance of $50 \mathrm{~mm}$ from each other. Two-photon excited fluorescence (TPEF) images and spectra of the lamellar silk scaffolds were acquired at 755 and $800 \mathrm{~nm}$ excitation with a Leica TCS SP2 (Wetzlar, Germany) spectral confocal microscope equipped with a Mai-Tai Ti:Sapphire laser. The lamellar thickness (T) and interlamellar distance (ID) were calculated using the Leica Confocal Software according to Fig. 2. Ten measurements per condition were obtained.

\subsection{Degree of hydration}

The degree of hydration of the porous constructs after the different treatments was investigated. All the samples were weighed before and after immersion in phosphate buffer solution (PBS) (at $37^{\circ} \mathrm{C}$ ) for different time intervals up to $1 \mathrm{~h}$. At each time, the samples were removed from the flasks and immediately weighed to (determine) wet weight as function of the immersion time:

$W_{\text {absorbed }}=\frac{\left(m_{\mathrm{f}}-m_{\mathrm{i}}\right)}{m_{\mathrm{i}}} \times 100 \%$

where $m_{\mathrm{i}}$ is the initial weight of the sample, and $m_{\mathrm{f}}$ is the sample wet weight after a given time of immersion.

\subsection{Fourier transformed infrared spectroscopy with attenuated total reflectance}

Fourier transformed infrared spectroscopy with attenuated total reflectance (FTIR-ATR) analysis of treated samples was performed in a Bruker Equinox 55/S FTIR spectrometer (Ettlingen, Germany), equipped with a deuterated triglycine sulfate detector and a multiple-reflection, horizontal MIRacle ATR attachment (using a Ge crystal, Pike Tech.). The instrument was continuously purged by nitrogen, using blow-off from a liquid nitrogen tank to eliminate the spectral contributions of atmospheric water vapor. For each treated sample, a measurement of 66 scans was collected at a resolution of $4 \mathrm{~cm}^{-1}$, which was acquired over a wavenumber range of $400-4000 \mathrm{~cm}^{-1}$. Spectral manipulations were performed with OPUS (Version 5.5, Bruker Optics, Inc.). Quantification of silk secondary structure was based on analyzing the amide I region (1600-1700 $\mathrm{cm}^{-1}$ ) [38]. Background absorption due to water was subtracted from the sample spectra to obtain a flat recording in the range of $1750-2000 \mathrm{~cm}^{-1}$ [39]. The amide I region (1600$1710 \mathrm{~cm}^{-1}$ ) was selected from the entire spectrum, and a linear baseline was applied to the spectrum. Deconvolution was carried out using 12 fixed fitting peak values as reported previously $[40,41]$. To confirm that each fitting peak position represented a real spectral signal signature from the silk film sample, second derivative analysis was performed on spectra from each processing condition. Second derivative analysis was carried out using a third degree polynomial function with a 9-point Savitski-Golay smoothing function $[39,42]$. During the deconvolution process, the peak positions were held constant for each sample to enable future comparisons between processing groups for protein secondary structure content. A Levenberg-Maquardt function available in the program was used for initial curve fitting. The curve fit was then refined using a local least squares fit, and the peak positions were reset to their initial positions if needed. The Levenberg-Maquardt function was used again for a final fit refinement. Throughout the process, the deconvoluted peak shapes were assumed to be Lorentzian [43]. The average per cent composition of fibroin secondary structure for the series of samples $[40,44]$, specifically the 

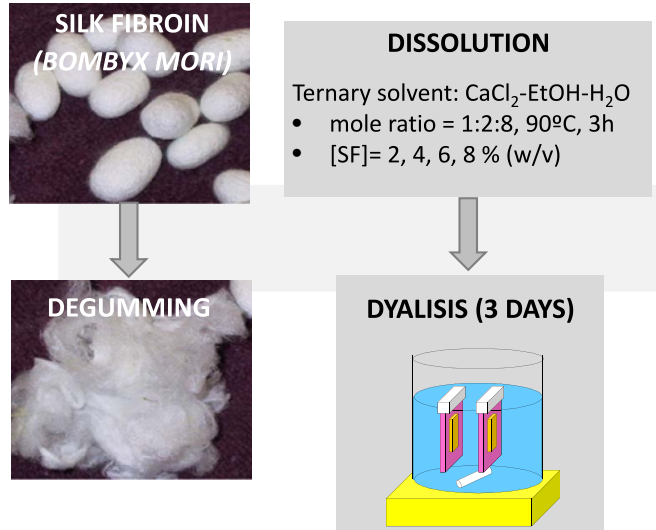

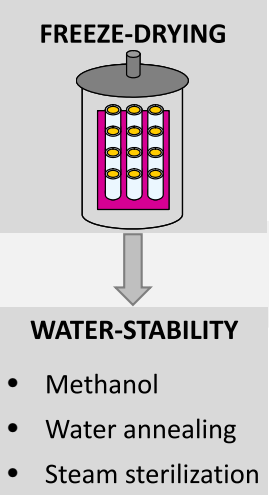

Fig. 1. Schematic drawing of the procedure for producing the SF lamellar scaffolds.
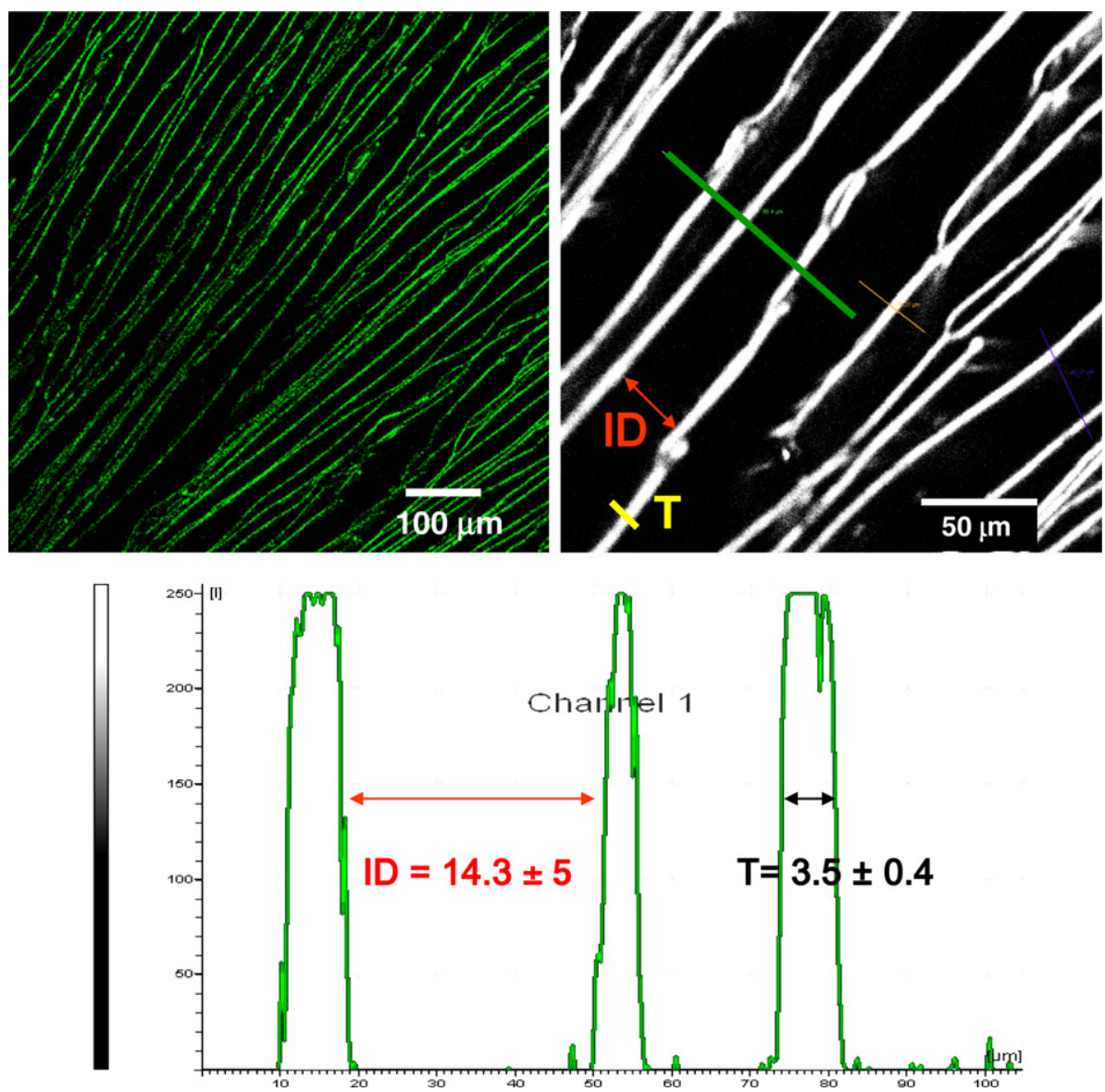

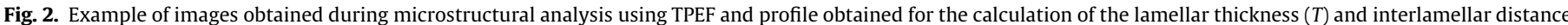
(ID).

amount of $\beta$-sheet structure, was assessed by integrating the area of each deconvoluted curve and then normalizing to the total area of the amide I region of the fitted spectra.

\subsection{Unconfined compression tests}

Unconfined compression tests were performed on an Instron 3366 testing frame (USA) equipped with a $100 \mathrm{~N}$ capacity load cell and custom-designed testing jig. Tests were conducted at room temperature in wet conditions (soaking in PBS), and five samples were used per condition. A displacement control mode was used, with a crosshead displacement rate of $5 \mathrm{~mm} \mathrm{~min}^{-1}$. The compressive stress and strain were graphed, and the yield strength as well as the compressive modulus and standard deviation were determined. The elastic modulus was calculated based on a semi-automatic technique. The stress-strain diagram was segmented into eight sections between the 0 and 10\% strain range (starting at a $15 \mathrm{~N}$ nominal tare load defined as $0 \%$ strain). Using least-squares fitting, the highest slope among these eight sections was defined as the compressive modulus for the sample. A line was drawn parallel to the modulus line, but offset by $2 \%$ of the sample gauge length. The corresponding stress value at which the offset line 
crossed the stress-strain curve was defined as the compressive yield strength of the scaffold.

\subsection{Human bone marrow stem cell isolation and expansion}

Total bone marrow $\left(25 \mathrm{~cm}^{3}\right.$, Cambrex, Walkersville, MD) was diluted in $100 \mathrm{ml}$ of medium (10\% fetal bovine serum (FBS)) and prepared as previously reported [1]. In brief, cells were separated by density gradient centrifugation with 20-ml aliquots of bone marrow suspension overlaid onto a poly-sucrose gradient $\left(1077 \mathrm{~g} \mathrm{~cm}^{-3}\right.$; Histopaque, Sigma, St. Louis, MO) and centrifuged at $800 \times$ for $30 \mathrm{~min}$ at room temperature. Cells were pelleted and suspended in expansion medium ( $\alpha$-MEM, 10\% FBS, $1 \mathrm{ng} \mathrm{ml}^{-1} \mathrm{bFGF}, 100 \mathrm{U} \mathrm{ml}^{-1}$ penicillin, $100 \mathrm{mg} \mathrm{ml}^{-1}$ streptomycin, $0.25 \mathrm{mg} \mathrm{ml}^{-1}$ fungizone, $0.1 \times 10^{-3} \mathrm{M}$ non-essential amino acids) and seeded in $75-\mathrm{cm}^{2}$ flasks at a density of $5 \times 10^{4}$ cells $\mathrm{cm}^{-2}$. The adherent cells were allowed to reach $\sim 80 \%$ confluence ( $12-17 \mathrm{~d}$ for the first passage). Cells used for the experiments were trypsinized, replated and passage 2 (P2) cells (80\% confluence after 6-8 d).

\subsection{In vitro culture}

For examination of cell growth and differentiation in vitro on the silk scaffolds, P2 hMSC $\left(1 \times 10^{6}\right.$ cells scaffold $\left.^{-1}\right)$ were seeded onto pre-wetted (a-MEM, overnight) scaffolds (7 mm diameter, $4 \mathrm{~mm}$ thick). Five constructs per condition were placed into 6 -well plates with osteogenic medium, placed in a humidified incubator at $37^{\circ} \mathrm{C} /$ $5 \% \mathrm{CO}_{2}$. Medium was replaced at a rate of $50 \%$ every $2-3 \mathrm{~d}$ for $21 \mathrm{~d}$. Osteogenic media consisted of $\alpha$-MEM supplemented with $10 \%$ FBS, $0.1 \times 10^{-3} \mathrm{M}$, non-essential amino acids, $50 \mu \mathrm{g} \mathrm{ml}^{-1}$, ascorbic acid2 -phosphate, $10^{-8} \mathrm{M}$ dexamethasone, $10 \times 10^{-3} \mathrm{M} \beta$-glycerophosphate and $1 \mu \mathrm{g} \mathrm{ml}^{-1} \mathrm{BMP}-2$ in the presence of $100 \mathrm{U} \mathrm{ml}^{-1}$ penicillin, $100 \mathrm{mg} \mathrm{ml}^{-1}$ streptomycin and $0.25 \mu \mathrm{g} \mathrm{ml}^{-1}$ fungizone.

\subsection{Calcium deposition assay}

Calcium deposition was assessed by Sigma Calcium Kit solution. Scaffolds samples were chopped into fine pieces in $500 \mu \mathrm{l}$ \% trichloroacetic acid, and the supernatants were combined for assay according to the manufacturers' protocol. Results were read at $575 \mathrm{~nm}$ by a VERSAmax microplate reader and normalized by the standards.

\subsection{Pico green DNA quantification assay and ALP assay}

DNA content and cell proliferation were assessed by Pico Green DNA Quantification Assay (Molecular Probes, Eugene, OR). Scaffold samples were chopped into fine pieces in $250 \mu \mathrm{l} 0.2 \%$ Triton 100 , and $80 \mu \mathrm{l}$ were taken for Pico green assay. Samples were read at $480 \mathrm{~nm} / 528 \mathrm{~nm}$ in a SpectraMas/GeminiEm fluorescence microplate reader and normalized by standards supplied by the kit. Alkaline phosphatase (ALP) activity was determined with an ALP kit from Sigma Diagnostics. A $120-\mu$ l aliquot of supernatant in $0.2 \%$ Triton was taken for ALP assay following the manufacturers' protocol. The conversion of $p$-nitrophenyl phosphate (colorless) to $p$ nitrophenol (yellow) was read at $405 \mathrm{~nm}$ in the same spectrometer as for the Picrogreen analysis. ALP activity was normalized by DNA content to display the ALP secreting amount per cell.

\section{Results}

\subsection{Microstructural evolution of the scaffolds}

Silk-based porous structures presenting different morphologies were successfully developed using a freeze-drying technique. Fig. 3 presents a phase diagram indicating the influence of the solute concentration and initial freezing temperature on the resulting microstructure.

SF solutions at different concentrations were frozen at $-80^{\circ} \mathrm{C}$. In this case, the effect of SF concentration on the resulting scaffold morphology was visualized from stage I to stage III. At low concentrations up to $4 \%(\mathrm{w} / \mathrm{v})$, a fibrous structure was obtained (stage I). With increased concentration of SF, the microstructure gradually changed towards a lamellar morphology (III). SF solutions with a concentration of $8 \%(\mathrm{w} / \mathrm{v})$ were frozen at $-5^{\circ} \mathrm{C}$ and $-80^{\circ} \mathrm{C}$. The effect of the initial freezing temperature was observed by comparing stage III with stage IV. The morphology in this case changed into a globular shape when the freezing temperature was raised from $-80^{\circ} \mathrm{C}$ to $-5^{\circ} \mathrm{C}$. For all the structures obtained, the pore morphology generated after drying was a replica of the ice crystal shape that was formed during freezing. Therefore, to produce freezedried structures with controlled lamellar-like architecture, a stable dendritic ice crystal morphology without any side branches has to be formed during freezing [24,26]. This effect was observed for concentrations $>6 \%$, when SF solution presented a higher viscosity and for freezing temperatures of $-80^{\circ} \mathrm{C}$. During the freezing process, SF was rejected from the solidification front and concentrated in the non-crystallized channels between the plate-like dendrites, as illustrated in Fig. 3.

\subsection{Structural integrity after inducing water stability}

After optimizing the processing parameters towards a controlled lamellar morphology, scaffolds were produced from SF solutions with a concentration of $8 \%$ and submitted to different crystallization processes to induce water stability, namely a methanol treatment, water annealing and steam sterilization. The structural integrity of the scaffolds after the different crystallization methods is presented in Fig. 4.

Fig. 4a-c corresponds to the original structure of the material, before any crystallization treatment. Comparison of the different crystallization methods for inducing water stability in the SF scaffolds developed shows that both water annealing (Fig. 4d-f) and methanol (Fig. 4g-i) treatments induced some deformation in the lamellar structure. Some of the lamella collapsed, compromising the initial porosity of the construct. Additionally, in the case of methanol treatment, a shrinkage of $\sim 20 \%$ was observed as a result of the drying process. In the case of the water annealing treatment, a swelling of the lamella was observed, due to the incorporation of water into the structure. When steam sterilization was used (Fig. $4 \mathrm{j}-1$ ), the integrity of the lamellar structure was fully maintained. Besides the sterilization effect, this method was effective in preserving the original size and shape of the lamella and consequently, the constructs.

Fig. 5 presents the average lamellar thickness and interlamellar distance of the scaffolds. Given the geometry of the pores, it is more relevant to evaluate the appropriateness of the interlamellar distances to allow cell ingrowth than to evaluate the scaffold's porosity.

As presented in Fig. 5a, the lamellar thicknesses were between $2.6 \pm 0.3 \mu \mathrm{m}$ for the methanol-treated scaffolds and $5.8 \pm 0.9 \mu \mathrm{m}$ for water-annealed scaffolds. These values are in the range of those reported for human lamellar bone, which are between 3 and $5 \mu \mathrm{m}$ thick [33]. Comparison of the cross section of the lamella before and after the different crystallization treatments shows an increase in thickness after the water-based annealing procedure. This effect is consistent with observations by SEM (Fig. 4). As a result, the space between the lamella also increased (Fig. 5b), indicating that there was an expansion in the scaffold structure during this process. When the methanol treatment was used, a slight decrease in thickness was observed. During the drying process, some of the lamella collapsed (Fig. 4g-i), and therefore the interlamellar 


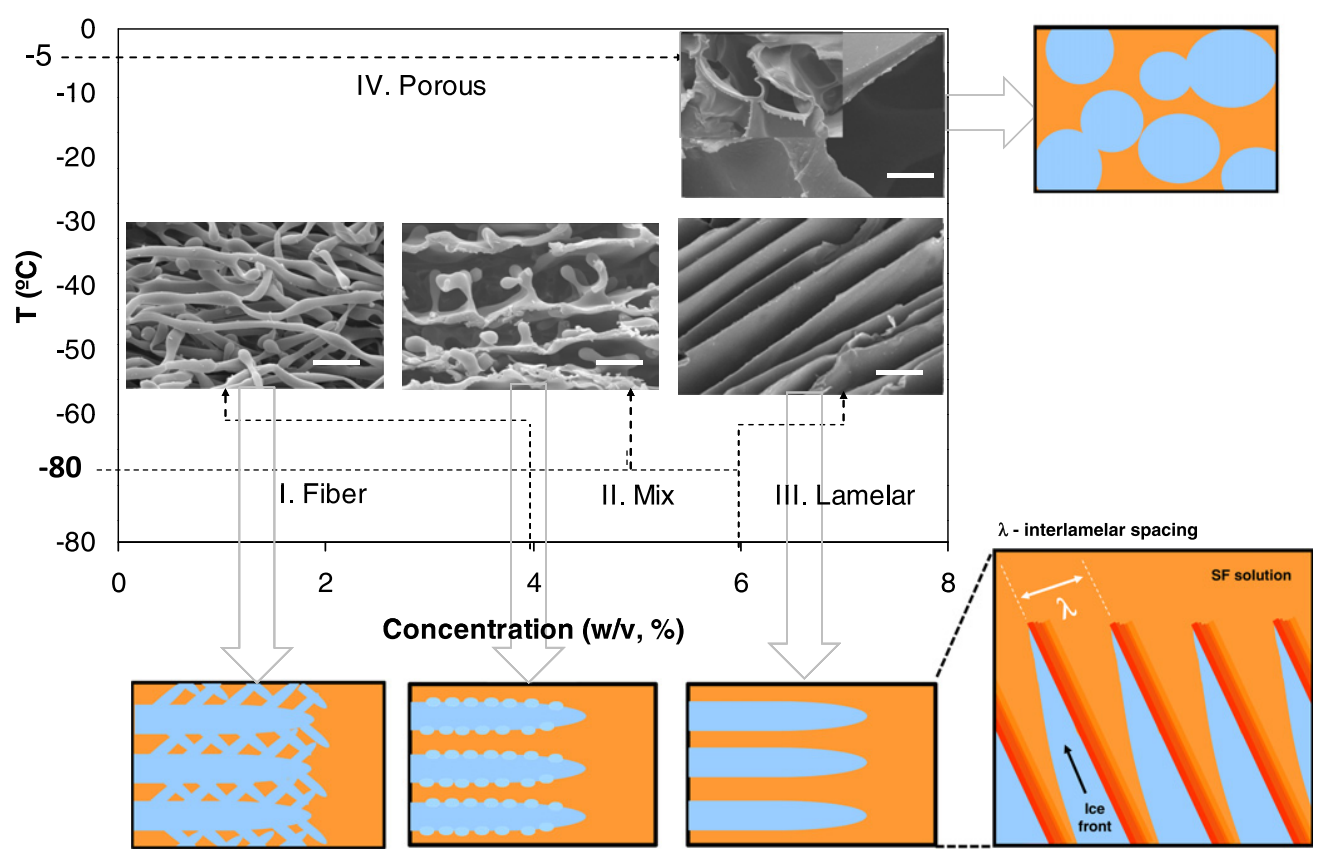

Fig. 3. Microstructural evolution of the SF scaffolds produced by freeze-drying. Scale bar: $10 \mu \mathrm{m}$.

distance was variable and difficult to determine, also leading to high error bars. For the autoclaved scaffolds, the thickness of the lamella did not vary and also the interlamellar distance did not change.

\subsection{Chemical structure}

Fig. 6 shows the original FTIR spectra of the samples before and after the different crystallization treatments. The assignment of the vibrational bands is made by reference to the literature, where treatments comparable with SF are reported for methanol [49], water annealing [42] and steam sterilization [50]. An example of a fitted spectrum of amide I with the individual deconvoluted peaks is also presented. Fourier transform self-deconvolution was used to determine the fractional contributions to the FTIR amide I absorbance spectrum for the untreated samples in comparison with each crystallization treatment.

Table 1 lists the wavenumber ranges corresponding to the characteristic vibrational bands in $B$. mori silk within the amide I region of the spectrum. The calculated values for the contributions to amide I are presented in Table 2, indicating the structural changes in the SF scaffolds induced by the different treatments.

As presented in Fig. 6a, the untreated freeze-dried scaffolds initially exhibited mostly an amorphous structure $\left(1542 \mathrm{~cm}^{-1}\right)$ with silk I structure $\left(1652 \mathrm{~cm}^{-1}\right)$. The majority of the silk matrix was composed of amorphous silk I structures (i.e., random coil, $\alpha$-helix and turn structures, in total $\sim 91 \%$ ). After the water annealing treatment, silk I was still predominant $\left(1653 \mathrm{~cm}^{-1}\right)$, although the amount of $\beta$-sheet conformation increased from $\sim 9$ to $\sim 24 \%$ (Table 2). Upon exposure to methanol and steam sterilization, a peak shift was observed located at 1626 and $1625 \mathrm{~cm}^{-1}$, respectively. In both cases, such shifts indicate increased silk II $\beta$-sheet content with a simultaneous reduction in silk I content with bands in the range $1610-1630 \mathrm{~cm}^{-1}$ region $[40,44]$. In both cases, the total $\beta$ sheet content increased to $\sim 51 \%$ (Fig. $6 \mathrm{~b}$, Table 2 ). Similar values have been reported previously for both treatments $[41,43]$. For steam sterilization treatment, water vapor and pressure promoted $\beta$-sheet crystallization to $>50 \%$. The random coil and $\alpha$-helix secondary structures exhibited the largest decrease in structure con- tent for steam sterilized and methanol treatment, compared with untreated and water-annealed samples. While turn structures exhibited a decrease in structure content for methanol-treated samples, this decrease was not significant in the case of the water vapor-mediated processes, i.e., water annealing and steam sterilization.

\subsection{Compression properties}

Fig. 7 presents the mechanical behavior of the lamellar structures following the different crystallization methods after being subjected to unconfined compression forces.

Comparison of the different crystallization methods shows that both the stiffness and the compressive strength of the materials were affected. With the steam sterilization treatment, there was a significant increase in both the stiffness and the strength of the materials compared with the methanol treatment. The stiffness increased from $75.1 \pm 25.2$ to $290.0 \pm 49.2 \mathrm{kPa}$, while the strength increased from $10.8 \pm 2.5$ to $22.5 \pm 3.1 \mathrm{kPa}$. This effect was the result of the application of the combined effect of water, temperature and pressure, which did not allow for changes in the structure during the conformational changes that occurred in the material.

\subsection{Degree of hydration}

The degree of hydration of the materials before and after the different crystallization treatments is represented in Fig. 8.

A higher degree of hydration was observed for the steam sterilization treatment, with mean values $>800 \%$. Methanol-treated samples also adsorbed similar amounts of PBS. In contrast, the degree of hydration achieved by the samples treated by the waterannealing process was considerably lower. Given the lamellar morphology of the scaffolds, the ability to hydrate is based on a capillary effect [45]. In the case of methanol, although a more hydrophobic structure was generated, the materials had more flexibility when immersed in PBS (as demonstrated in Fig. 7 by the lower mechanical properties in PBS). While the fluid was being adsorbed into the structure, the lamellae that were initially collapsed recovered their shape, allowing the structure to expand. This 

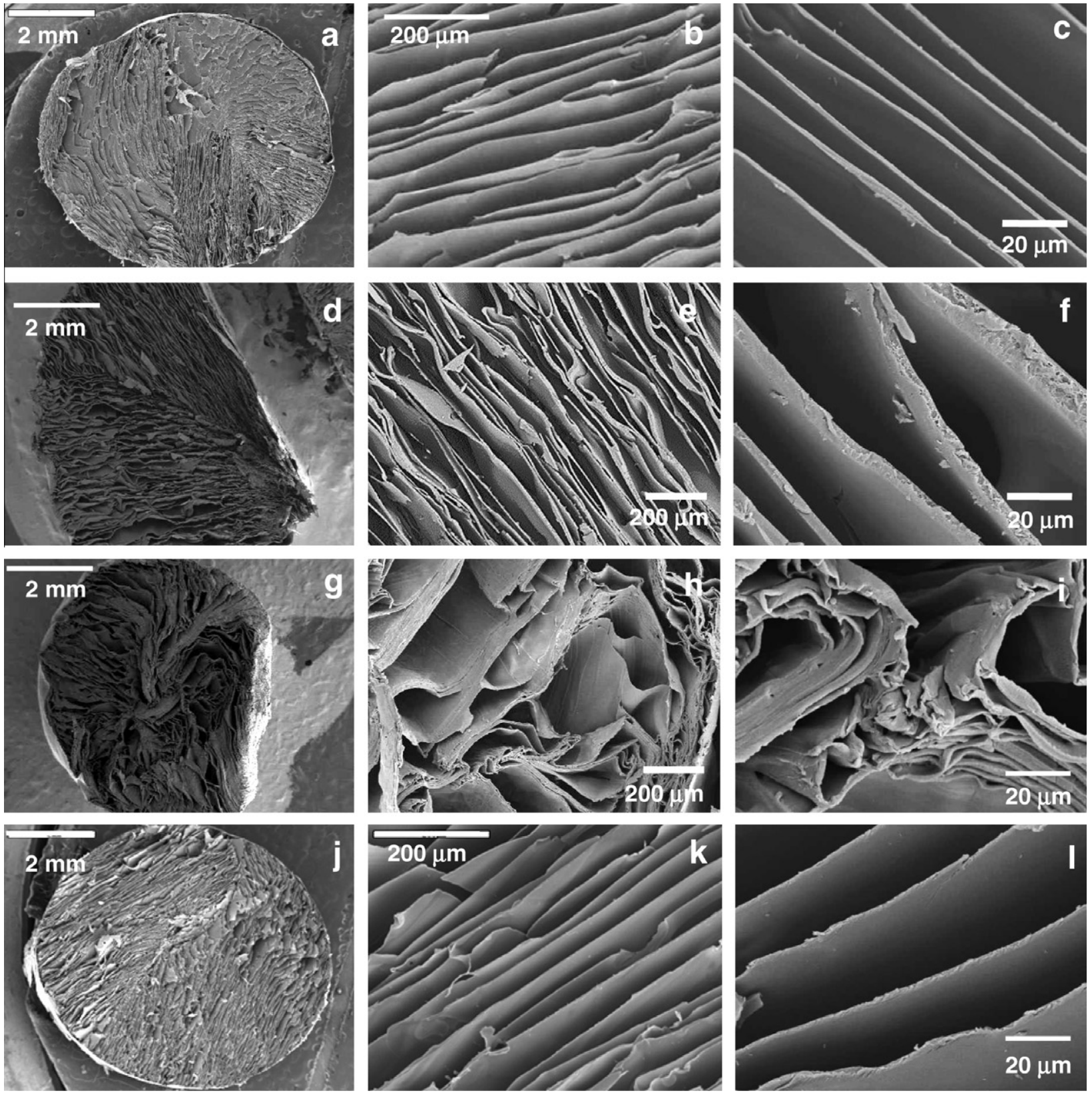

Fig. 4. SEM micrographs showing the morphology of the cross sections of the scaffolds $(a-c)$ untreated and after the different crystallization methods: (d-f) water annealing; (g-i) methanol treatment; and $(\mathrm{j}-\mathrm{l})$ steam sterilization.

phenomenon was observed by confocal microscopy, as presented in Fig. 9.

In this case, since there was sufficient realignment of the lamella, an average lamellar distance of $20 \pm 6 \mu \mathrm{m}$ was achieved (calculated for the structures immersed in PBS). In the case of steam sterilization, a high degree of hydration was also observed. Again a physical phenomenon seems to control the process. Although this structure presented the highest values for stiffness and strength, the fact that the structure preserved its initial highly aligned morphology allowed for a higher absorption of PBS under the time-frames evaluated.

\subsection{Cell morphology}

To address the effect of the chemical structure and lamellar morphology on the biological response of the materials, hMSC were seeded on the scaffolds treated with methanol (highest $\beta$ sheet content, lowest lamellar thickness, high hydration degree) and by the water-annealing process (lowest $\beta$-sheet content, highest lamellar thickness, low hydration degree). TPEF images were acquired, as presented in Fig. 10.

TPEF images reveal in green the lamellar morphology obtained after freeze-drying and subsequent stabilization treatments of methanol (Fig. 10a) and water annealing (Fig. 10d). The presence of collagen on the constructs cultured after 3 weeks, based on second harmonic generation, is presented in red (Fig. 10b and e). Collagen is aligned with the lamella, particularly in the case of the methanol treatment. The lamellar morphology constituted a patterned surface onto which hMSC attached and proliferated and guided the formation of the extracellular matrix (ECM). SEM analysis was performed to the cross section of the scaffolds after cell culture for 3 weeks (Fig. 11). 
a. Lamellar thickness

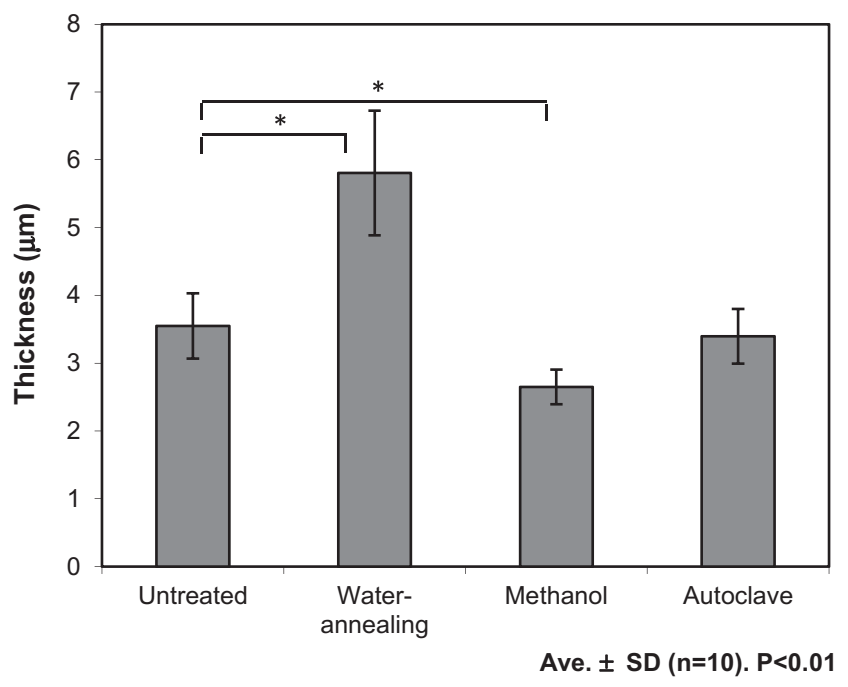

b. Interlamellar distance

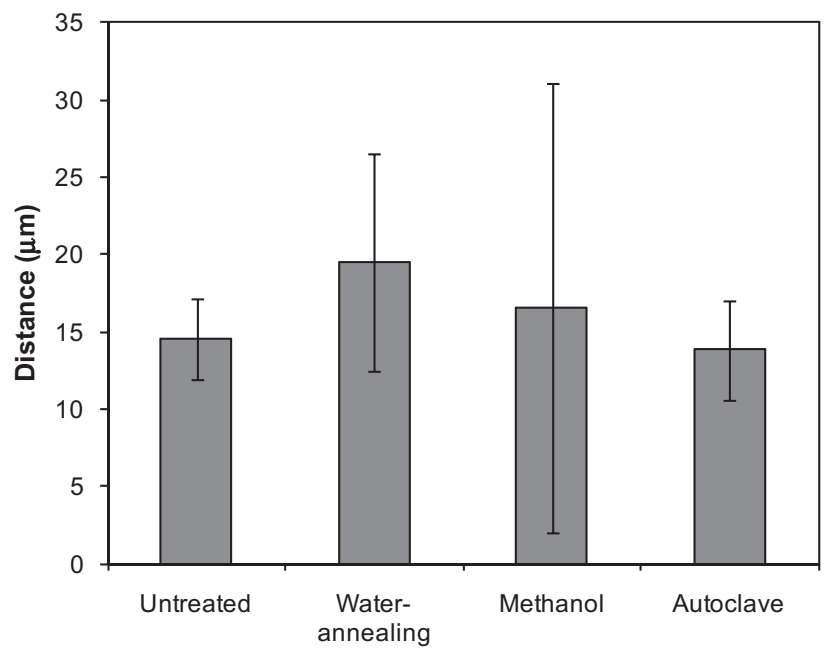

Fig. 5. (a) Average lamellar thickness and (b) interlamellar distance of the scaffolds untreated and after the different crystallization methods.
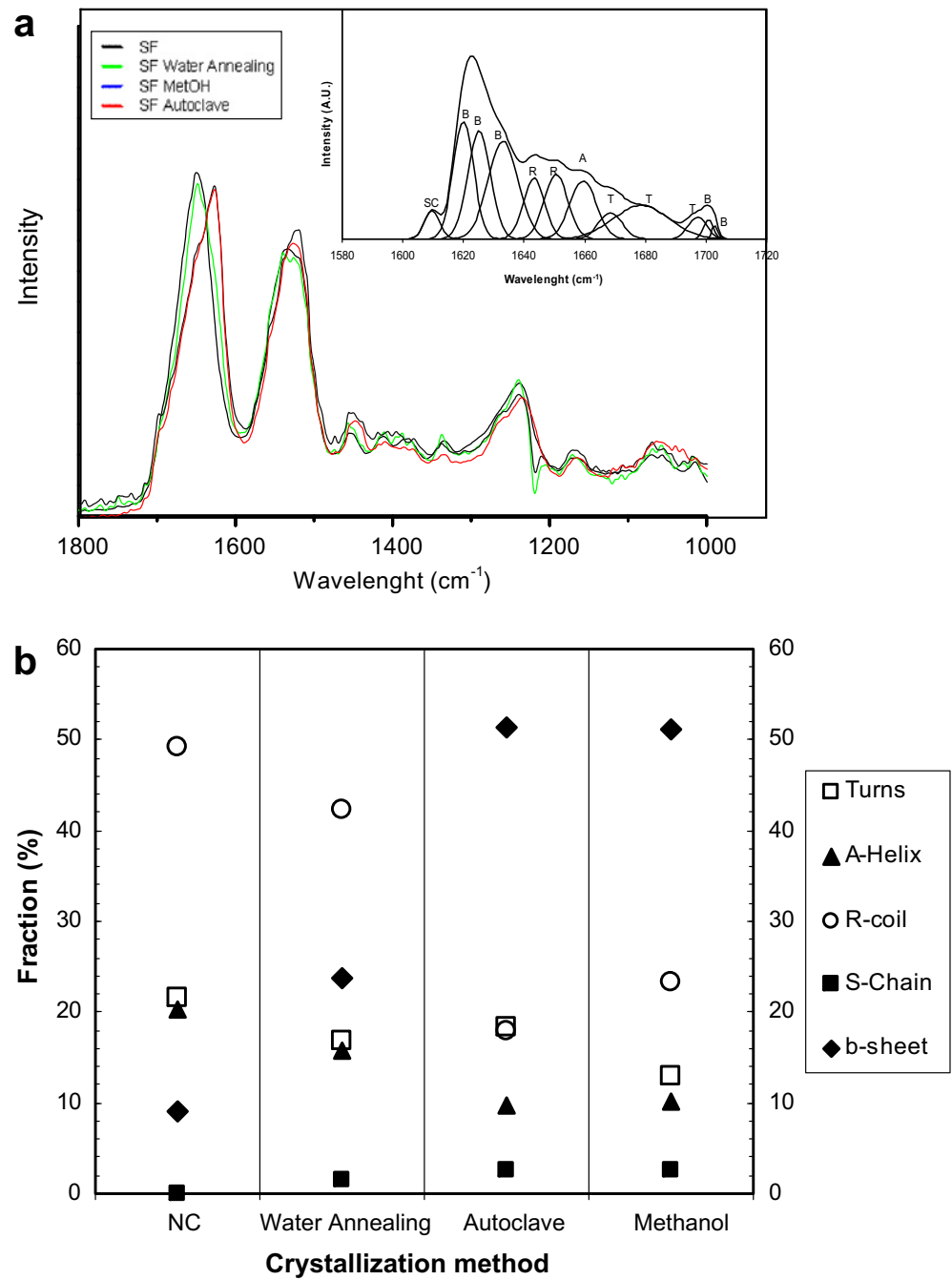

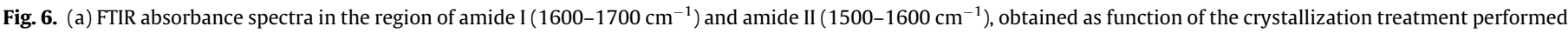

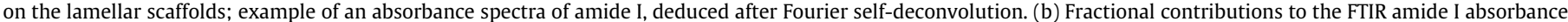

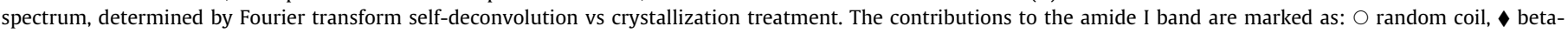
sheets, $\boldsymbol{\Delta}$ alpha-helices, $\square$ turns, and $\mathbf{\square}$ side chains. 
Table 1

Vibrational band assignments for the amide I region of SF $[41,48]$.

\begin{tabular}{|c|c|}
\hline Wavenumber range $\left(\mathrm{cm}^{-1}\right)$ & Secondary structure assignment \\
\hline $1605-1615$ & (Tyr) side chains/aggregated strands \\
\hline $1616-1621$ & Aggregate $\beta$-strand/sheet (weak) ${ }^{\mathrm{a}}$ \\
\hline $1622-1627$ & $\beta$-Sheets (strong) ${ }^{\mathrm{a}}$ \\
\hline $1628-1637$ & $\beta$-Sheets (strong) ${ }^{\mathrm{b}}$ \\
\hline $1638-1646$ & Random coils/extended chains \\
\hline $1647-1655$ & Random coils \\
\hline $1656-1662$ & $\alpha$-Helix \\
\hline $1663-1670$ & Turns \\
\hline $1671-1670$ & Turns \\
\hline $1671-1685$ & Turns \\
\hline 1686-1695 & Turns \\
\hline $1697-1703$ & $\beta$-Sheets (weak) ${ }^{a}$ \\
\hline
\end{tabular}

a Intermolecular $\beta$-sheets.

b Intramolecular $\beta$-sheets.

Table 2

Calculated values for the contributions to amide I.

\begin{tabular}{lclcc}
\hline & NC & Water annealing & Autoclave & Methanol \\
\hline$\beta$-Sheet & 9.02 & 23.70 & 51.26 & 51.24 \\
Turns & 21.50 & 16.81 & 18.39 & 12.87 \\
$\alpha$-Helix & 20.28 & 15.74 & 9.79 & 10.16 \\
R-coil & 49.19 & 42.28 & 17.98 & 23.20 \\
S-chain & 0 & 1.47 & 2.66 & 2.52 \\
Silk I & 90.97 & 76.30 & 48.82 & 48.75 \\
\hline
\end{tabular}

For the methanol-treated lamellar scaffolds, the presence of ECM was observed along $4 \mathrm{~mm}$ of the scaffolds' cross section, which indicates that the cells were able to migrate through the spaces between the lamella to the innermost region of the scaffolds. The scaffolds with this thickness and using methanol treatment therefore presented good interconnectivity, as it was possible to obtain layers of cells/ECM intercalated with the SF lamellas in a multi-layer assembly. In the case of the water-annealed scaffolds, this effect was not observed. Since the materials were not able to fully expand in solution, many of the layers remained collapsed, which compromised the overall interconnectivity.

\subsection{Biochemical analysis}

Fig. 12 presents the biochemical characterization of (a) DNA, (b) ALP and (c) $\mathrm{Ca}^{2+}$ for hMSC cells cultured up to 6 weeks.

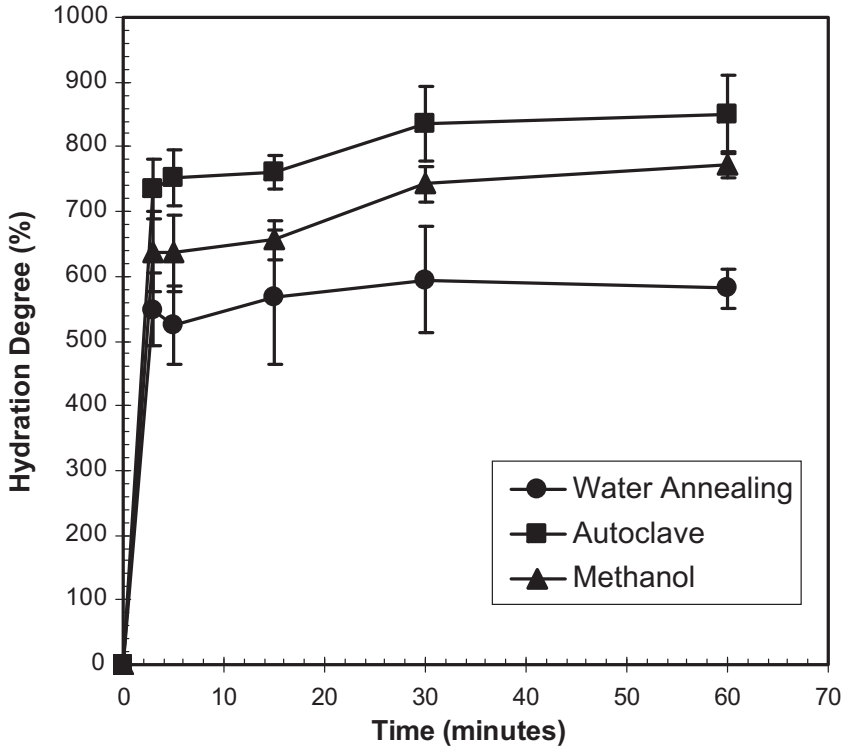

Fig. 8. Degree of hydration of the lamellar structures after immersion in PBS (at $\left.37^{\circ} \mathrm{C}\right)$.

The DNA content of the lamellar silk constructs was measured to quantify cell proliferation. The cell number after 1 day of seeding was higher in the water-annealed scaffolds compared with those treated with methanol $(p<0.05)$. This can be explained by a difference in the seeding efficiency. In the scaffolds treated with methanol, the cells could easily penetrate between the lamella, some being lost to the bottom of the well. In water-annealed scaffolds, the cells were mostly located at its surface, since the structure is more dense. After 42 days of culture, the cell number, as determined by DNA content, was significantly higher for water-annealed scaffolds (Fig. 12a). This result indicates that, at this stage, the differences in the chemical structure, mechanical properties and morphology of the constructs were relevant to stimulate cell proliferation. Still, one has to consider that in the water-annealed scaffolds most of the cells were located at the surface of the scaffolds, with better access to supply of oxygen and nutrients from the medium, which can have a consequence in the resulting cell numbers.

\section{Compression tests (unconfined mode)}
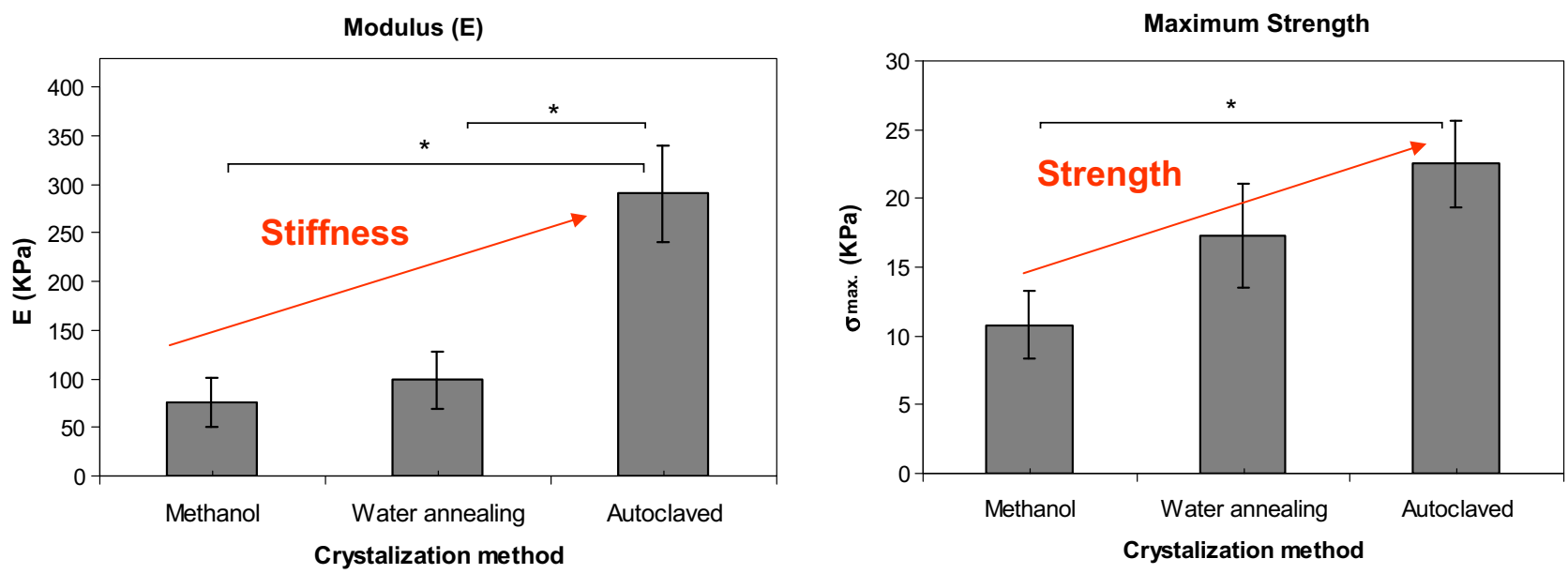

Ave. \pm SD $(n=5) . P<0.05$.

Fig. 7. Mechanical behavior under compression of the lamellar structures after the different crystallization treatments. 

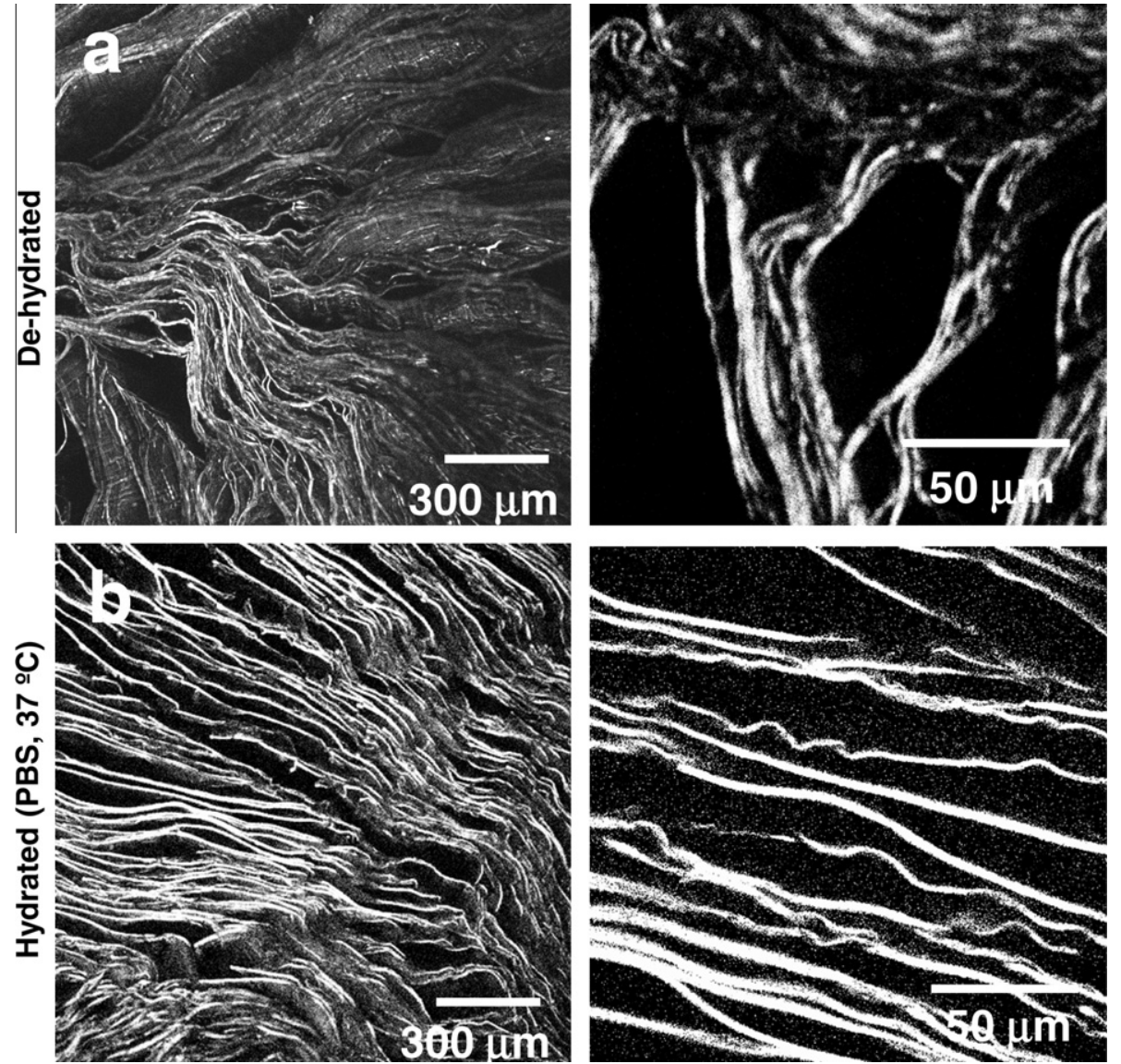

Fig. 9. Confocal micrographs of the lamellar scaffolds (a) dried after the methanol treatment and (b) after subsequent re-hydration in PBS solution at $37{ }^{\circ} \mathrm{C}$.
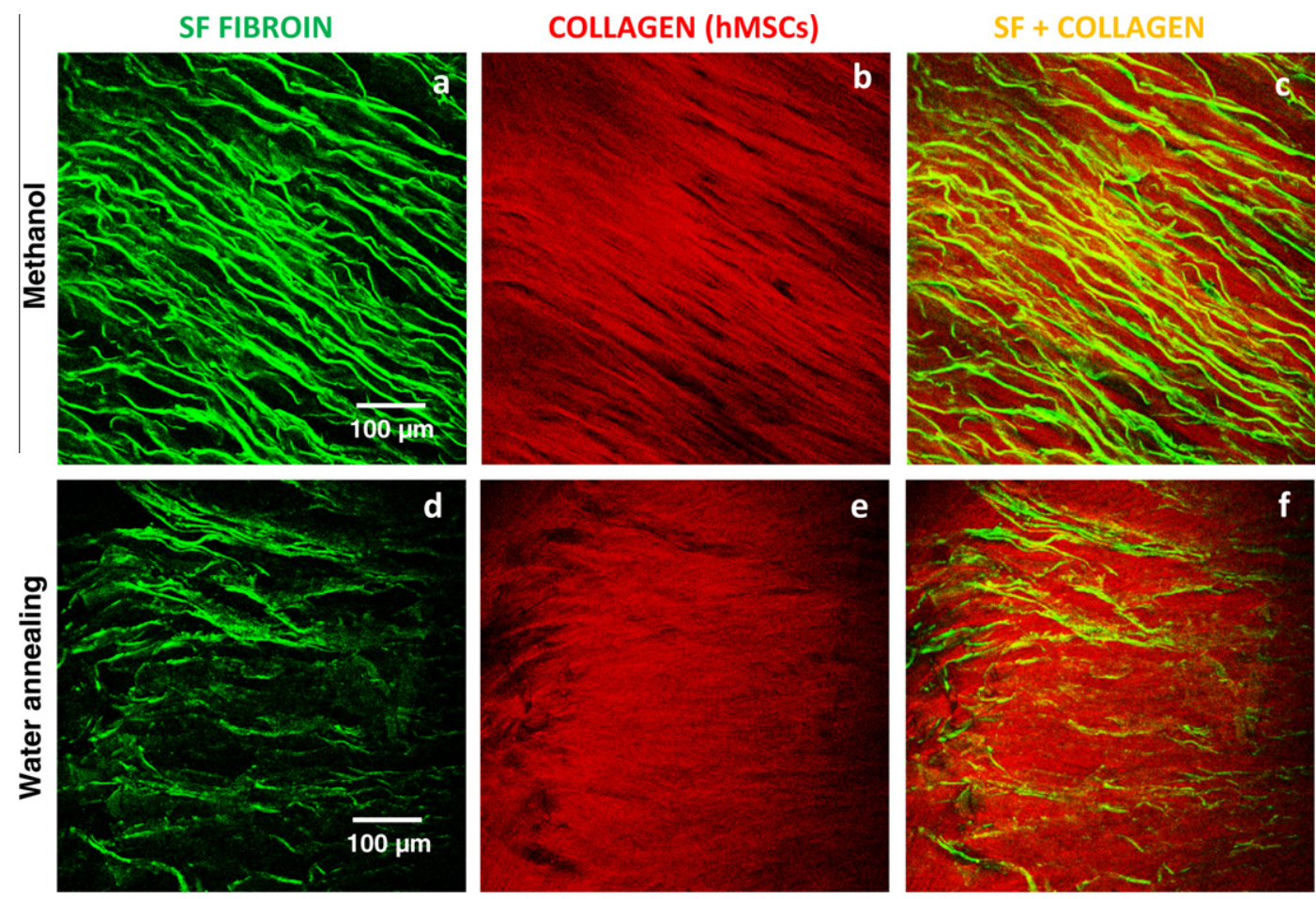

Fig. 10. Multi-photon microscopy evaluation of the lamellar 3-D scaffolds treated with methanol (a, b, c) and water annealing (d, e, f), after hMSCs culture for 3 weeks. TPEF image of the silk scaffolds in green (a, d). SHG signal from the deposited collagen in red (b, e). Combination of both images (c, f). 

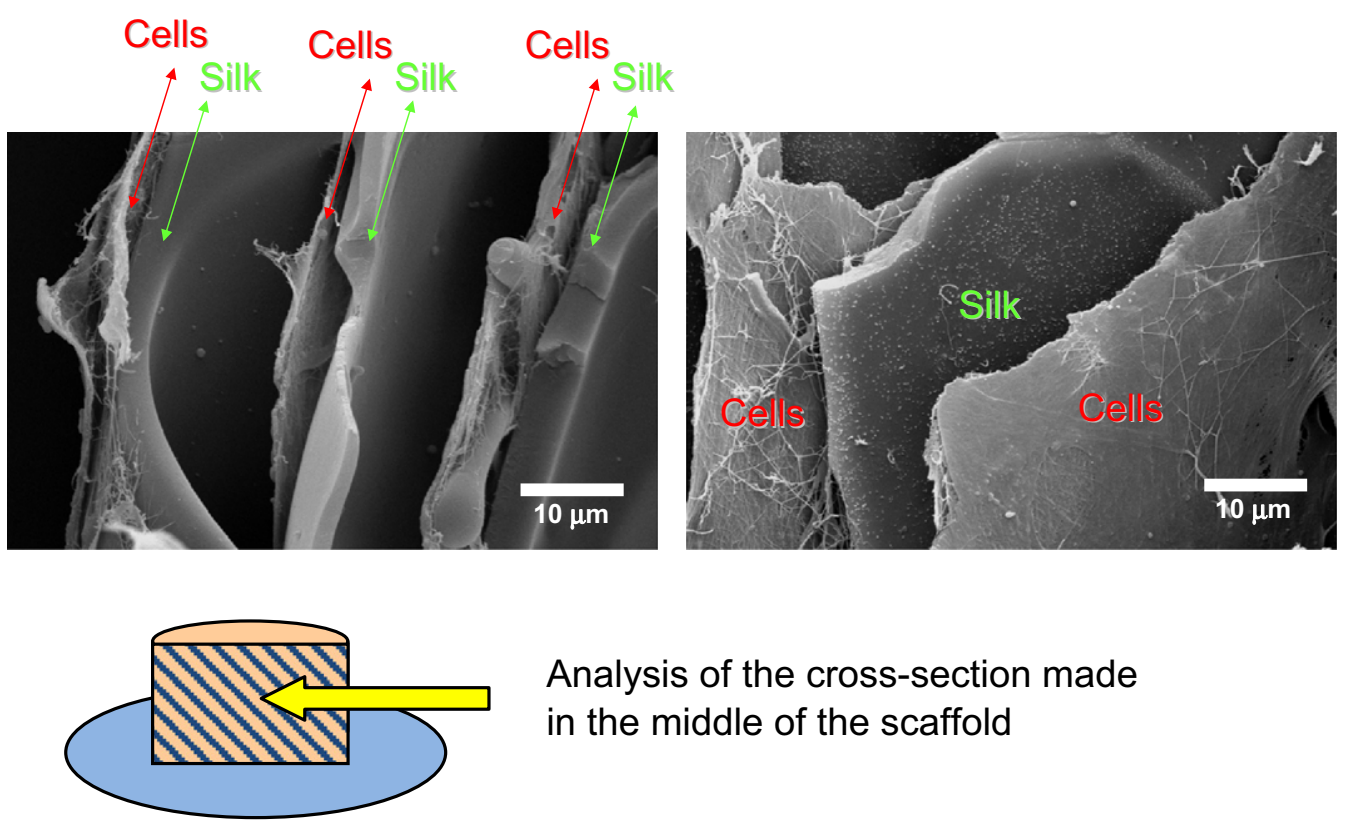

\section{Analysis of the cross-section made in the middle of the scaffold}

Fig. 11. SEM of a cross section of a lamellar scaffold treated with methanol, after culture with hMSC for 3 weeks.

ALP activity was determined for up to 42 days of culture (Fig. 12b). This biochemical assay is a marker of early osteoblastic differentiation and commitment of bone marrow stem cells toward the osteoblastic phenotype [46]. As expected, in the first 21 days there was a gradual increase in ALP in both the scaffolds treated with methanol and those treated with water annealing. There were no significant differences between the values obtained for the scaffolds treated with these procedures, although the mean values were consistently higher for the water-annealing process. After 42 days, this difference became significant $(p<0.05)$. To determine mineralized matrix deposition in the lamellar scaffolds, a calcium dissolution assay was conducted (Fig. 12c). During the first 21 days, there were no differences between the amount of mineralized matrix deposited in the methanol-treated scaffolds compared with those treated by the water-annealing process. However, at day 42 it was possible to observe an increase in $\mathrm{Ca}^{2+}$ for the water-annealed scaffolds, indicating that, in this environment, cells were able to produce more mineralized matrix.

\section{Discussion}

\subsection{Control of the microstructure of ice formation}

It is well established that the microstructural features obtained during freeze-drying are controlled mainly by exploiting the physics of ice formation $[24,26,34,47]$. In the present study, by controlling parameters such as the freezing temperature and the concentration of the silk solution, it was possible to modulate the morphology of the ice crystals to generate anisotropic porous scaffolds with a regular lamellar morphology. For the lowest freezing temperature used $\left(-80^{\circ} \mathrm{C}\right)$, a preferential growth direction was imposed on the ice crystals, which reflected in a highly oriented porous morphology. As previously described [26], the solidification occurs under a steady-state freezing regime, where the ice crystals exhibit a homogeneous morphology without any side branches throughout the construct. The growing ice crystals reject the dissolved silk and transfer heat from the moving interface of icewater into the remaining unfrozen water. Under these conditions of directional freezing, the solution concentrates in the phases be- tween the growing ice crystals, and an advancing solid/liquid interface is created [47]. The influence of the freezing rate on pore structure has been studied for collagen-based scaffolds [48], where the formation of ice crystals within the protein suspension was influenced by both the rate of nucleation of ice crystals and the rate of heat and protein diffusion.

Recently, there has been interest in the production of highly aligned polymeric structures, given their application potential. Directional freezing has been investigated as a simple strategy for the preparation of controlled aligned polymeric structures $[27,29-31,34,49-52]$. This process is based on traditional freezedrying, although it allows for controlling the movement of the freezing front, thereby creating well-structured materials with fewer defects. Aqueous polymer solutions, colloids or their mixtures have been aligned to form biomimetic structures for engineering tissues such as cartilage [28,51], peripheral nerves and the spinal cord [27-29,31,49,52]. In a work by Stokols and Tuszynski [29] the freeze-dry processing was used to create scaffolds from agarose, with uniaxial linear pores. Khang et al. [49] used freezedrying for fabrication tubular porous poly(L-lactide-co-glycolide) structures. Madaghiele et al. [31] developed cylindrical collagenbased scaffolds and axially oriented pore channels. Wu et al. [28] proposed new porous gelatin scaffolds with microtubule orientation using a unidirectional freeze-drying technology. Matrices with this porous structure have potential to improve the regeneration of tubular organ structures such as peripheral nerves and the spinal cord by physically supporting and guiding the growth of neural structures across the site of injury.

Matrices with a lamellar-like structure can find applications as lamellar bone and also in intervertebral disk (annulus fibrosus) regeneration. However, freeze-dried lamellar-like structures are not easy to obtain. To the authors' knowledge, few studies have reported the development of such architectures [30,32,53]. The major difficulty encountered is to achieve enough control during ice formation to avoid the formation of lamellar structures with defects such as those observed for instance in the morphologies reported by $\mathrm{Wu}$ et al. [28] and Kang et al. [53] for gelatin scaffolds or by Deville et al. [24] for hydroxyapatite slurries. Waschkies and co-workers [54] developed a procedure to control the freezing 

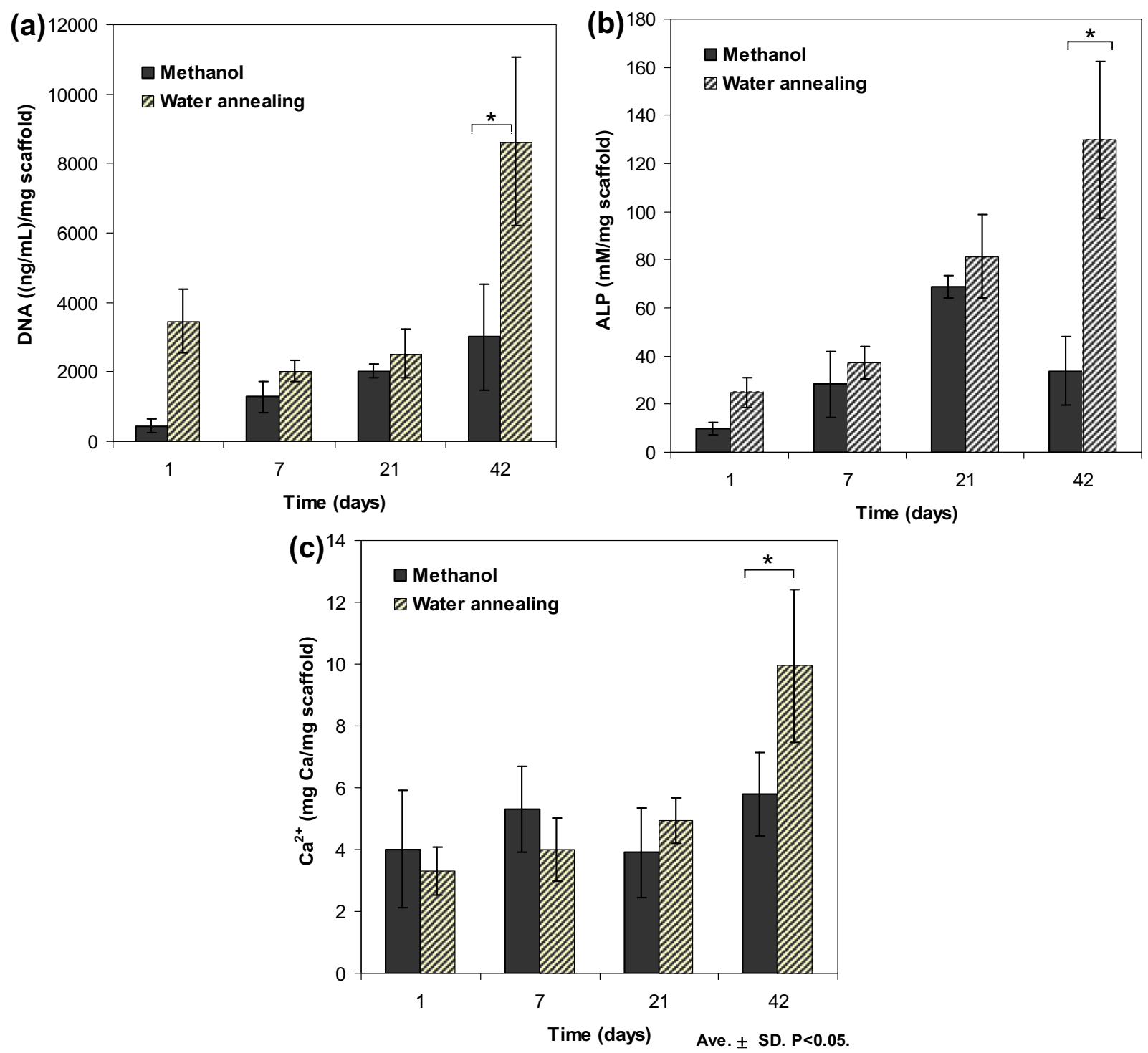

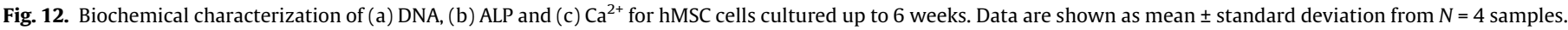
* represents statistically significant differences $(p<0.05)$.

process of alumina suspensions using a double-side cooling method. Using this setup and theoretical knowledge, they were able to control microstructure development over several centimeters. Nevertheless, some defects were observed.

The processing route proposed in the present work was effective in generating defect-free lamellar-like morphology with very regular lamellar thickness and interlamellar distance. In the present case, directional freezing was achieved by adjusting the freezing temperature, considering the cylinder geometry and scaffold volume. This morphology is known to improve the mechanical properties while reducing volume density, leading to unusually high compressive strength [24].

\subsection{Effect of the water stabilization treatment}

Different crystallization processes were proposed to induce water stability of the scaffolds. As expected, the methanol treatment was effective in generating $\beta$-sheets. A decrease in the thickness was observed, due to a contraction effect during transition to $\beta$-sheet conformation. Also, the materials suffered shrinkage during methanol evaporation, owing to capillary forces and stress development between lamellae, from the surface to the center during drying. Nevertheless, when rehydrated, the collapsed lamellae were able to realign and recover their initial shape to some extent. Water-annealing treatment also induced some distortion to the lamellar structure combined with an increase in the thickness of the layers. This structural adjustment can be explained by the increase in mobility of the SF chains due to the absorption of water and a decrease in the glass transition temperature $\left(T_{\mathrm{g}}\right)$, attributed to water molecules behaving as a plasticizer to allow greater intermolecular movement between fibroin protein chains [55-57]. Under these supersaturated conditions of humidity, a phase transition occurs, and the random coil form of SF is stabilized by hydration to yield a silk I structure [37]. When immersed in PBS solution, waterannealed constructs were not able recover the initial lamellar alignment.

Steam sterilization was effective in inducing $\beta$-sheet conformation without introducing dimensional variations to the scaffolds' morphology. Lawrence et al. [58] first introduced this treatment as a viable solvent-free methodology for water stability of cast SF membranes for corneal regeneration. The present work evaluated the suitability of this process to stabilize 3-D porous architectures, 
without compromising structural integrity. This treatment is inspired by the same principles as the water-annealing process, but it has the advantage of combining the effect of pressure and temperature to accelerate conformational changes, from the silk I to the more energetically favorable silk II state, thereby promoting more $\beta$-sheet formation. Hu et al. [57] studied the mechanism of structural evolution of SF during water annealing on samples at different temperatures $\left(4-100^{\circ} \mathrm{C}\right)$. According to their model, for the highest temperature studied, the water vapor molecules will bring thermal energy into the protein-bound water system, and the kinetics of crystal growth will increase. Considering the steam-sterilization treatment, this effect will be catalyzed by the presence of pressure in the system. In this way, higher crystallinity can be reached within a shorter time. The compressive stiffness and the strength of the resulting lamellar structures were significantly enhanced with this treatment compared with treatment by methanol or water-annealing.

The hydration capacity of the stabilized SF materials results from the combined effect of the surface properties with the bulk mechanical properties. The capillarity effect is a well-known phenomenon, which is dependent on the surface wettability [45]. Methanol treatment generates a higher content of $\beta$-sheet domains which are hydrophobic. In contrast, water-annealed scaffolds will be more hydrophilic. As reported, the contact angle of SF increases from 62.6 after water annealing to 71.4 for methanol treatment. In the case of the steam sterilization treatment, the contact angle value should be close to the methanol-treated surfaces, given the similar amount of $\beta$-sheet content. Therefore, it would be expected that the more hydrophilic materials, i.e., those treated by the water-annealing process, should exhibit a higher degree of hydration. From the materials chemistry perspective, the results seem contradictory. However, in this case the contribution of physical effects, such as the available interlamellar space and the mechanical properties exhibited by the materials when immersed in PBS, resulted in different outcomes concerning the capacity of fluid absorption. The water-annealed structures with a higher chemical affinity to water and already some degree of expansion presented the lowest degree of hydration. This was a result of higher resistance to dimensional change, as demonstrated by the mechanical performance during compression. These features probably did not allow for the full expansion of the structure when in contact with PBS for $60 \mathrm{~min}$. For the steam sterilization treatment, since the structural integrity of the materials was not compromised, the spaces between lamellae did not change, which favored the hydration process. This treatment was the most suitable for inducing water stability, while having the advantage of sterilizing the materials.

\subsection{In vitro cell behavior and spatial organization}

The biochemical results revealed that, in scaffolds treated by the water-annealing process, there was an increase in cell proliferation and subsequent ECM production [46]. This phenomenon was reported previously, comparing water-annealed membranes with those treated with methanol [37]. In this case, the differences in protein conformation and consequently in silk II content, crystallinity and wettability of the surface were the main factors associated with different cell behavior.

The different morphological features such as the lamellar thickness or interlamellar distance also seem to be responsible for the differences in cell activity. The lamellar constructs allowed hMSC to attach and proliferate, guiding the formation of ECM after 21 days of cell culture. For water-annealed scaffolds, the cells aligned mostly at the surface, which served as a pattern for cells to attach and proliferate for guiding matrix deposition. In the case of methanol-treated scaffolds, after immersion in culture medium, significant recovery of the initial morphology was observed due to a realignment of the lamella. This increase in interlamellar space allowed hMSC to attach, proliferate and align, progressing to the interior of the scaffold. Under this spatial confinement, these cells were able to produce highly aligned collagen matrix alternated with the SF lamellae in a multi-layer assembly. This kind of cell alignment following the morphology of the material can be useful in generating tissues with highly anisotropic properties. In this work, lamellar bone was envisioned to be a possible target application for these highly aligned laminated structures. However, given the ability of these structures to hydrate, several other applications can also be envisioned, such as for cartilage $[27,28,51]$. As reported by Almarza et al. [59], the importance of cell alignment in several biological tissues is to the optimization of function. Cell-matrix interactions are paramount for the successful repair and regeneration of damaged and diseased tissue. Since many tissues have an anisotropic architecture, it has been proposed that aligned ECM could guide and support the differentiation of resident MSC [5961]. The present results give some insight into the regulation of hMSC through directional ECM structures and demonstrate the potential of these 3-D lamellar structures as cell culture platforms for guiding the morphogenesis of anisotropic tissues. In addition, the preparation of highly aligned structures with aligned porosity in the micrometer range can be of technological importance for a wide range of other applications, such organic electronics, microfluidics and molecular filtration, among others.

\section{Conclusions}

A simple methodology for designing new SF materials with controlled lamellar morphology is presented. Steam sterilization was a suitable method for inducing water stability, preserving the structural integrity and improving mechanical properties, while also sterilizing the constructs. Methanol-treated scaffolds presented an adequate interlamellar distance for cell migration, resulting in the formation of layers of cells/ECM intercalated with the SF. Therefore, the lamellar morphology obtained allowed hMSC to attach and proliferate, guiding the formation of ECM. The results offer interesting possibilities for developing highly aligned structures and for the engineering of specific tissues where anisotropic properties are desirable.

\section{Acknowledgements}

A.L.O. wishes to thank financial support from the Portuguese Foundation for Science and Technology (SFRH/BPD/39102/2007) under POCTI Program. This work was partially supported by FCT through POCTI and/or FEDER programs and by the $\mathrm{NIH}$ [DE017207, EB003210 and EB002520].

\section{Appendix A. Figures with essential colour discrimination}

Certain figures in this article, particularly Figs. 1-3, 6, 7, and 1012 are difficult to interpret in black and white. The full colour images can be found in the on-line version, at doi:10.1016/ j.actbio.2011.12.015.

\section{References}

[1] Altman GH, Diaz F, Jakuba C, Calabro T, Horan RL, Chen J, et al. Silk-based biomaterials. Biomaterials 2003;24:401-16.

[2] Numata K, Cebe P, Kaplan DL. Mechanism of enzymatic degradation of betasheet crystals. Biomaterials 2010;31:2926-33.

[3] Jiang CY, Wang XY, Gunawidjaja R, Lin YH, Gupta MK, Kaplan DL, et al. Mechanical properties of robust ultrathin silk fibroin films. Adv Funct Mater 2007;17:2229-37. 
[4] Uebersax L, Hagenmueller H, Hofmann S, Gruenblatt E, Mueller R, VunjakNovakovic G, et al. Effect of scaffold design on bone morphology in vitro. Tissue Eng 2006;12:3417-29.

[5] Altman GH, Horan RL, Lu HH, Moreau J, Martin I, Richmond JC, et al. Silk matrix for tissue engineered anterior cruciate ligaments. Biomaterials 2002;23:4131-41.

[6] Chang G, Kim HJ, Kaplan D, Vunjak-Novakovic G, Kandel RA. Porous silk scaffolds can be used for tissue engineering annulus fibrosus. Eur Spine J 2007; 16:1848-57.

[7] Chao PHG, Yodmuang S, Wang XQ, Sun L, Kaplan DL, Vunjak-Novakovic G. Silk hydrogel for cartilage tissue engineering. J Biomed Mater Res B 2010;95B:84-90.

[8] Enomoto S, Sumi M, Kajimoto K, Nakazawa Y, Takahashi R, Takabayashi C, et al. Long-term patency of small-diameter vascular graft made from fibroin, a silkbased biodegradable material. J Vasc Surg 2010;51:155-64.

[9] Omenetto FG, Kaplan DL. New opportunities for an ancient material. Science 2010;329:528-31.

[10] Mandal BB, Park SH, Gil ES, Kaplan DL. Multilayered silk scaffolds for meniscus tissue engineering. Biomaterials 2011;32:639-51.

[11] Gomes S, Leonor IB, Mano JF, Reis RL, Kaplan DL. Spider silk-bone sialoprotein fusion proteins for bone tissue engineering. Soft Matter 2011;7:4964-73.

[12] Silva SS, Motta A, Rodrigues MT, Pinheiro AF, Gomes ME, Mano JF, et al. Novel genipin-cross-linked chitosan/silk fibroin sponges for cartilage engineering strategies. Biomacromolecules 2008;9:2764-74.

[13] Bessa PC, Balmayor ER, Cerqueira MT, Rada T, Gomes ME, Neves NM, et al. Silk nanoparticles for delivery of human BMP-2 in bone regenerative medicine applications. Tissue Eng Pt A 2008;14:776-7.

[14] Liao S, Chan CK, Ramakrishna S. Stem cells and biomimetic materials strategies for tissue engineering. Mater Sci Eng C: Bio S 2008;28:1189-202.

[15] Wheeldon I, Farhadi A, Bick AG, Jabbari E, Khademhosseini A. Nanoscale tissue engineering: spatial control over cell-materials interactions. Nanotechnology 2011;22:212001.

[16] Hutmacher DW, Sittinger M, Risbud MV. Scaffold-based tissue engineering: rationale for computer-aided design and solid free-form fabrication systems. Trends Biotechnol 2004;22:354-62.

[17] Alves NM, Pashkuleva I, Reis RL, Mano JF. Controlling cell behavior through the design of polymer surfaces. Small 2010;6:2208-20.

[18] Pirraco RP, Marques AP, Reis RL. Cell interactions in bone tissue engineering. J Cell Mol Med 2010;14:93-102.

[19] Kang CE, Gemeinhart EJ, Gemeinhart RA. Cellular alignment by grafted adhesion peptide surface density gradients. J Biomed Mater Res A 2004;71A:403-11.

[20] Dado D, Levenberg S. Cell-scaffold mechanical interplay within engineered tissue. Semin Cell Dev Biol 2009;20:656-64.

[21] Kim JH, Cho CS, Choung YH, Lim KT, Son HM, Seonwoo H, et al. Mechanical stimulation of mesenchymal stem cells for tissue engineering. Tissue Eng Regen Med 2009;6:199-206.

[22] Tandon N, Cannizzaro C, Chao PH, Maidhof R, Marsano A, Au HT, et al. Electrical stimulation systems for cardiac tissue engineering. Nat Protoc 2009;4:155-73.

[23] Torbet J, Malbouyres M, Builles N, Justin V, Roulet M, Damour O, et al. Orthogonal scaffold of magnetically aligned collagen lamellae for corneal stroma reconstruction. Biomaterials 2007;28:4268-76.

[24] Deville S, Saiz E, Nalla RK, Tomsia AP. Freezing as a path to build complex composites. Science 2006;311:515-8.

[25] Zmora S, Glicklis R, Cohen S. Tailoring the pore architecture in 3-D alginate scaffolds by controlling the freezing regime during fabrication. Biomaterials 2002;23:4087-94.

[26] Schoof H, Bruns L, Fischer A, Heschel I, Rau G. Dendritic ice morphology in unidirectionally solidified collagen suspensions. J Cryst Growth 2000;209:122-9.

[27] Lee MK, Chung NO, Lee J. Membranes with through-thickness porosity prepared by unidirectional freezing. Polymer 2010;51:6258-67.

[28] Wu X, Liu Y, Li X, Wen P, Zhang Y, Long Y, et al. Preparation of aligned porous gelatin scaffolds by unidirectional freeze-drying method. Acta Biomater 2010;6:1167-77.

[29] Stokols S, Tuszynski MH. The fabrication and characterization of linearly oriented nerve guidance scaffolds for spinal cord injury. Biomaterials 2004;25:5839-46.

[30] Schoof H, Apel J, Heschel I, Rau G. Control of pore structure and size in freezedried collagen sponges. J Biomed Mater Res 2001;58:352-7.

[31] Madaghiele M, Sannino A, Yannas IV, Spector M. Collagen-based matrices with axially oriented pores. J Biomed Mater Res A 2008;85:757-67.

[32] Deville S. Freeze-casting of porous ceramics: a review of current achievements and issues. Adv Eng Mater 2008;10:155-69.
[33] Weiner S, Traub W, Wagner HD. Lamellar bone: structure-function relations. J Struct Biol 1999;126:241-55.

[34] Zhang H, Hussain I, Brust M, Butler MF, Rannard SP, Cooper AI. Aligned twoand three-dimensional structures by directional freezing of polymers and nanoparticles. Nat Mater 2005;4:787-93.

[35] Kim HJ, Kim HS, Matsumoto A, Chin IJ, Jin HJ, Kaplan DL. Processing windows for forming silk fibroin biomaterials into a 3D porous matrix. Aust $\mathrm{J}$ Chem 2005;58:716-20.

[36] Kim HJ, Kim UJ, Leisk GG, Bayan C, Georgakoudi I, Kaplan DL. Bone regeneration on macroporous aqueous-derived silk 3-D scaffolds. Macromol Biosci 2007;7:643-55.

[37] Jin HJ, Park J, Karageorgiou V, Kim UJ, Valluzzi R, Kaplan DL. Water-stable silk films with reduced beta-sheet content. Adv Funct Mater 2005;15:1241-7.

[38] Arrondo JLR, Prado A, Echabe I, Goni FM. Protein conformational-changes induced by surfactants as studied by FT-IR. Biophys J 1993;64:A382.

[39] Dong A, Huang P, Caughey WS. Protein secondary structures in water from 2nd-derivative amide-I infrared-spectra. Biochemistry 1990;29:3303-8.

[40] Tretinnikov ON, Tamada Y. Influence of casting temperature on the nearsurface structure and wettability of cast silk fibroin films. Langmuir 2001;17:7406-13.

[41] Hu X, Kaplan D, Cebe P. Determining beta-sheet crystallinity in fibrous proteins by thermal analysis and infrared spectroscopy. Macromolecules 2006;39:6161-70.

[42] Speare JO, Rush TS. IR spectra of cytochrome c denatured with deuterated guanidine hydrochloride show increase in beta sheet. Biopolymers 2003;72:193-204.

[43] Matsumoto A, Chen J, Collette AL, Kim UJ, Altman GH, Cebe P, et al Mechanisms of silk fibroin sol-gel transitions. J Phys Chem B 2006;110:21630-8.

[44] Wilson D, Valluzzi R, Kaplan D. Conformational transitions in model silk peptides. Biophys J 2000;78:2690-701.

[45] Israelachvili JN, Mcguiggan PM. Forces between surfaces in liquids. Science $1988 ; 241: 795-800$

[46] Stein GS, Lian JB, Owen TA, Bortell R, Vanwijnen AJ, Bidwell JP, et al. Integrated relationship of proliferation and differentiation during osteoblast phenotype development. Frontiers of osteosarcoma research; 1993. p. 387-401.

[47] Butler MF. Freeze concentration of solutes at the ice/solution interface studied by optical interferometry. Cryst Growth Des 2002;2:541-8.

[48] O'Brien FJ, Harley BA, Yannas IV, Gibson L. Influence of freezing rate on pore structure in freeze-dried collagen-GAG scaffolds. Biomaterials 2004:25:1077-86.

[49] Khang G, Jeon JH, Cho JC, Lee HB. Fabrication of tubular porous PLGA scaffold by emulsion freeze-drying method. Polymer (Korea) 1999;23:471-7.

[50] Kim G, Ahn S, Kim Y, Cho Y, Chun W. Coaxial structured collagen-alginate scaffolds: fabrication, physical properties, and biomedical application for skin tissue regeneration. J Mater Chem 2011;21:6165-72.

[51] Liu Y, Wen P, Gao JP, Zhang YL, Li XL, Long Y, et al. Fabrication of chitosan scaffolds with tunable porous orientation structure for tissue engineering. J Biomater Sci: Polym Ed. 2011;22:19-40.

[52] Sannino A, Madaghiele M. Tuning the porosity of collagen-based scaffolds for use as nerve regenerative templates. J Cell Plast 2009;45:137-55.

[53] Kang HW, Tabata Y, Ikada Y. Fabrication of porous gelatin scaffolds for tissue engineering. Biomaterials 1999;20:1339-44.

[54] Waschkies T, Oberacker R, Hoffmann MJ. Control of lamellae spacing during freeze casting of ceramics using double-side cooling as a novel processing route. J Am Ceram Soc 2009;92:S79-84.

[55] Hu X, Kaplan D, Cebe P. Effect of water on the thermal properties of silk fibroin. Thermochim Acta 2007;461:137-44.

[56] Agarwal N, Hoagland DA, Farris RJ. Effect of moisture absorption on the thermal properties of Bombyx mori silk fibroin films. J Appl Polym Sci 1997;63:401-10.

[57] Hu X, Shmelev K, Sun L, Gil ES, Park SH, Cebe P, et al. Regulation of silk material structure by temperature-controlled water vapor annealing. Biomacromolecules 2011;12:1686-96.

[58] Lawrence BD, Omenetto F, Chui K, Kaplan DL. Processing methods to control silk fibroin film biomaterial features. J Mater Sci 2008;43:6967-85.

[59] Almarza AJ, Yang G, Woo SL, Nguyen T, Abramowitch SD. Positive changes in bone marrow-derived cells in response to culture on an aligned bioscaffold. Tissue Eng Part A 2008;14:1489-95.

[60] Qi X, Ye J, Wang Y. Alginate/poly (lactic-co-glycolic acid)/calcium phosphate cement scaffold with oriented pore structure for bone tissue engineering. Biomed Mater Res A 2009;89:980-7.

[61] Lanfer B, Seib FP, Freudenberg U, Stamov D, Bley T, Bornhauser M, et al. The growth and differentiation of mesenchymal stem and progenitor cells cultured on aligned collagen matrices. Biomaterials 2009;30:5950-8. 